\title{
ANALYSIS OF COMBINED FoOTINGS ON EXTENSIBLE GEOSYNTHETIC- STONE COLUMN IMPROVED GROUND
}

\author{
Priti Maheshwari ${ }^{1}$ \\ ${ }^{1}$ Department of Civil Engineering, Indian Institute of Technology Roorkee, Roorkee 247667, India.
}

Date received: 27/04/2017, Date accepted: 25/08/2017

Corresponding author's email: priti_mahesh2001@yahoo.com

\begin{abstract}
Analysis of combined footings resting on an extensible geosynthetic reinforced granular bed on stone column improved ground has been carried out in the present work. Various components of soil-foundation system have been idealized using lumped parameter modeling approach as: combined footing as finite length beam, granular layer as nonlinear Pasternak shear layer, geosynthetic reinforcement as elastic extensible membrane, stone columns as nonlinear Winkler springs and foundation soil as nonlinear Kelvin body. Hyperbolic constitutive relationships have been adopted to represent the nonlinear behavior of various elements of a soil-foundation system. Finite difference method has been employed to solve developed governing differential equations with the help of appropriate boundary and continuity conditions. A detailed parametric study has been conducted to study the effect of model parameters like applied load, flexural rigidity of footing, configuration of stone columns, ultimate bearing resistance of foundation soil and stone columns, tensile stiffness of geosynthetics and degree of consolidation on response of soil-foundation system by means of deflection and bending moment in the footing and mobilized tension in geosynthetic layer. These parameters have been found to have significant influence on the response of footing and the geosynthetic reinforcement layer. To quantify this, results have been nondimensionalized to produce design charts for ready use for the analysis of combined footings resting on such a soilfoundation system.
\end{abstract}

Keywords: Combined footings, extensible geosynthetic layer, stone columns, nonlinearity.

\subsection{INTRODUCTION}

Currently, various ground improvement measures have been adopted to enhance bearing capacity of foundations and reduce total as well as differential settlements. Use of stone columns and geosynthetics are some of the commonly adopted means for the improvement of earth beds. Various experimental, analytical and numerical studies have been conducted to study the response of such soil-foundation systems. Modeling of geosynthetics is done as an elastic membrane or as a beam possessing finite flexural rigidity. For geosynthetic reinforcement layers modelled as a membrane, if the modulus of elasticity of the reinforcement layer is very large in comparison to that of the soil, the reinforcement layer is treated to be inextensible. For such type of reinforcement, the compatibility of displacements requires that the displacements of the points in the soil along the interface are zero. For extensible reinforcement, the ratio of moduli of elasticity of reinforcement and the soil is moderate. Compatibility of deformations requires that displacements of reinforcement and the soil along the interface should be the same, i.e., no slip condition.

Some of the studies pertaining to analysis of stone columns that have dealt with soft soil foundation systems include Balaam and Booker [1], Alamgir et al. [2], Shahu et al. [3] etc. Analyses in which the ground was treated with the geosynthetic as a measure of ground improvement find mention in Madhav and Poorooshasb [4], Ghosh and Madhav [5], Shukla and Chandra [6], Yin [7], Maheshwari et al. [8] etc. A close look on these studies suggests that soft soil was either reinforced with stone columns or with geosynthetic layers. However, Deb et al. [9, 10] combined both the measures of ground improvement and presented simple models for analysis of geosynthetic - reinforced granular fill - soft soil with stone column systems by considering the inextensible and extensible nature of the geosynthetic layer respectively. However, the foundation was not modelled in the analysis. Only the load coming from the foundation was taken into account directly on the treated ground. To remove this limitation, Maheshwari and Khatri [11] modelled the combined footing as a beam resting on a geosynthetic - reinforced granular fill - stone column improved soft soil system. The geosynthetic layer 
was assumed to behave as an inextensible rough elastic membrane. Zhou et al. [12] proposed an analytical model for the analysis of geosynthetic reinforced embankment. Embankment fill was modeled as a Timoshenko beam imbedded with a geosynthetic layer and the pavement was idealized as an Euler-Bernoulli beam. Rajesh et al. [13] developed a foundation model for predicting the behavior of a geosynthetic reinforcement railway track system resting on soft clay subgrade. The geosynthetic layer was represented by a stretched rough elastic membrane. Burger model was used to characterize the soft clay subgrade. Zhao et al. [14] proposed a dual beam model for a geosynthetic-reinforced granular fill with an upper pavement. The upper pavement was modeled by an Euler-Bernoulli beam while the geosynthetic reinforced granular fill was simulated by a reinforced Timoshenko beam.

A critical review of literature suggests the absence of any study pertaining to settlement analysis of shallow foundations possessing finite flexural rigidity on extensible geosynthetic reinforced - granular fill - soft soil with stone columns system. A simple mechanical model has therefore been proposed in the present work for such an analysis. The governing differential equations have been derived considering free body diagrams of various components of a soil-foundation system. Further, these have been solved with appropriate boundary and compatibility conditions employing finite difference method.

\subsection{ANALYSIS}

\subsection{Development of mathematical model}

A combined footing subjected to column loads $\left(\mathrm{Q}_{1}, \mathrm{Q}_{2}\right.$ and $\left.\mathrm{Q}_{3}\right)$ has been considered for the analysis. As shown in Fig. 1, the footing is resting on a geosynthetic reinforced granular layer. This layer is lying on soft foundation soil treated with stone columns. Length of footing has been considered as $2 \mathrm{~B}$ while the extent of geosynthetic is up to $2 \mathrm{~L}$. Diameter and spacing of stone columns has been represented as $\mathrm{d}$ and $\mathrm{s}$ respectively. Geosynthetic layer has been placed in between the granular layer with thicknesses and shear moduli as $\mathrm{H}_{\mathrm{t}}, \mathrm{H}_{\mathrm{b}}$ and $\mathrm{G}_{\mathrm{t}}, \mathrm{G}_{\mathrm{b}}$ respectively. As the geosynthetic has been assumed to be extensible in nature, its tensile stiffness is represented by $E_{\mathrm{g}}$. This soil-foundation system has been modeled employing lumped parameter modeling and presented in Fig. 2. The footing has been modeled as a beam, the granular layer as a nonlinear Pasternak shear layer, the geosynthetic as a linear, rough, elastic, extensible membrane, the soft foundation soil as a nonlinear Kelvin body and the stone columns as nonlinear Winkler springs. The nonlinear nature has been modeled with the help of Kondner's hyperbolic constitutive relationship.

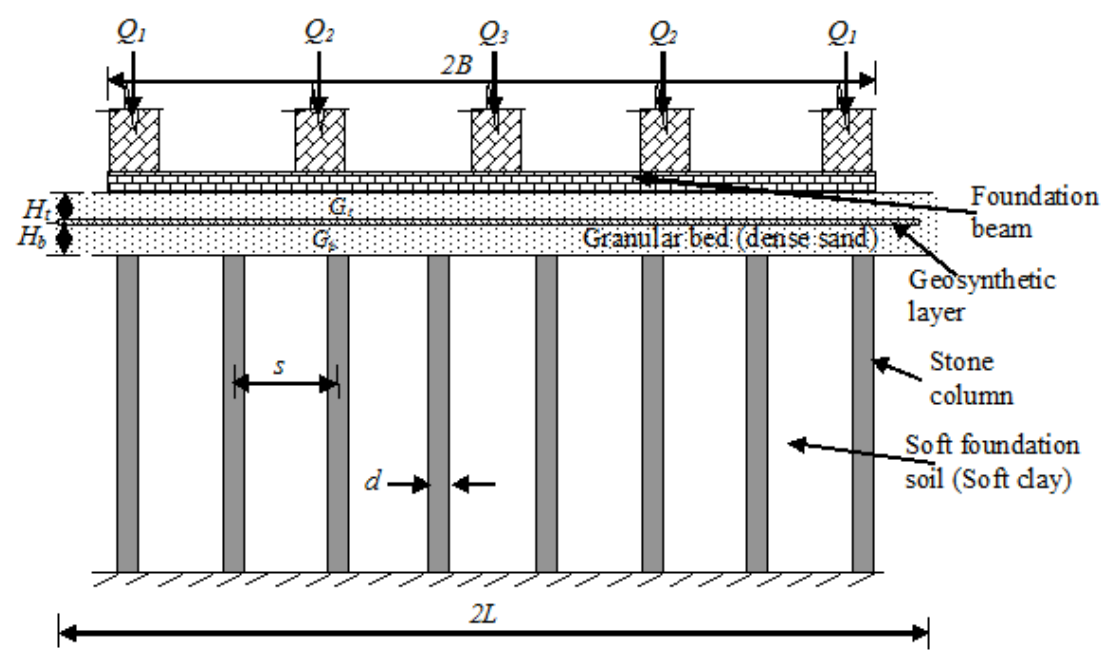

Figure 1 Definition sketch of the problem

Considering the equilibrium of free bodies of various components of the soil-foundation system and imposing the deformation compatibility conditions, the governing differential equations of the foundation model can be expressed as [7] - 


$$
\begin{aligned}
q=q_{s} & -T \cos ^{3} \theta \frac{d^{2} w}{d x^{2}}-\sin \theta \frac{d T}{d x}-\left(H_{t} G_{t}^{1}+H_{b} G_{b}^{1}\right) \frac{d^{2} w}{d x^{2}} \\
\frac{d^{2} T}{d x^{2}}= & \sin \theta \cos \theta \frac{d^{2} w}{d x^{2}} \frac{d T}{d x}+\frac{1}{\cos \theta}\left(\frac{G_{t}^{o}}{H_{t}}+\frac{G_{b}^{o}}{H_{b}}\right)\left[\sqrt{\left(\frac{T}{E_{g}}+1\right)^{2}-\left(\frac{d w}{d x}\right)^{2}}-1\right] \\
& +\frac{H_{b}}{H_{t}}\left(\frac{G_{t}^{o}}{\tau_{u b}}-\frac{G_{b}^{o}}{\tau_{u t}} \frac{G_{t o}}{G_{b o}} \frac{G_{t}^{1}}{G_{b}^{1}}\right) \frac{G_{b}^{o} H_{t}}{\left(G_{t}^{o} H_{b}+G_{b}^{o} H_{t}\right)} \frac{d^{2} w}{d x^{2}} \frac{d T}{d x}
\end{aligned}
$$

where, $q$ is the reaction of the soil on beam; $q_{s}$, the vertical reaction pressure of soft soil/stone column; $T$, the mobilised tension in geosynthetic layer; $\theta$, the slope of geosynthetic layer element [7]; $w$, the vertical displacement of beam; $d x$, the projected element length in $x$ direction; $E_{g}$, the tensile stiffness $(\mathrm{N} / \mathrm{m})$ of geosynthetic layer; $G_{t o}$ and $G_{b o}$, the initial shear modulus of top and bottom shear layers respectively; $\tau_{u t}$ and $\tau_{u b}$, the ultimate shear resistance of the top and bottom shear layers respectively. $G_{t}^{o}, G_{b}^{o}, G_{t}^{1}$, and $G_{b}^{1}$ are defined as follows:

$$
\begin{aligned}
& G_{t}^{o}=\frac{G_{t o}}{1+\frac{G_{t o}}{\tau_{u t}}\left|\frac{d w}{d x}\right|} ; G_{b}^{o}=\frac{G_{b o}}{1+\frac{G_{b o}}{\tau_{u b}}\left|\frac{d w}{d x}\right|} \text { and } \\
& G_{t}^{1}=\frac{G_{t o}}{\left[1+\frac{G_{t o}}{\tau_{u t}}\left|\frac{d w}{d x}\right|\right]^{2}}, G_{b}^{1}=\frac{G_{b o}}{\left[1+\frac{G_{b o}}{\tau_{u b}}\left|\frac{d w}{d x}\right|\right]^{2}}
\end{aligned}
$$

The vertical reaction pressure, $q_{s}$ can be written as [11]-

$$
\begin{aligned}
& q_{s}=\frac{k_{s o} w}{U\left[1+k_{s o}\left(w / q_{u}\right)\right]} \text {, within the soft soil region } \\
& \text { and } q_{s}=\frac{k_{c o} w}{1+k_{c o}\left(w / q_{c u}\right)} \text {, within the stone column region }
\end{aligned}
$$

where, $k_{s o}$ and $k_{c o}$ are the initial modulus of subgrade reaction for saturated soft soil and the stone columns respectively; $q_{u}$ and $q_{c u}$, the ultimate bearing resistance of soft soil and the stone columns respectively and $U$, the average degree of consolidation at any time $t>0$. 


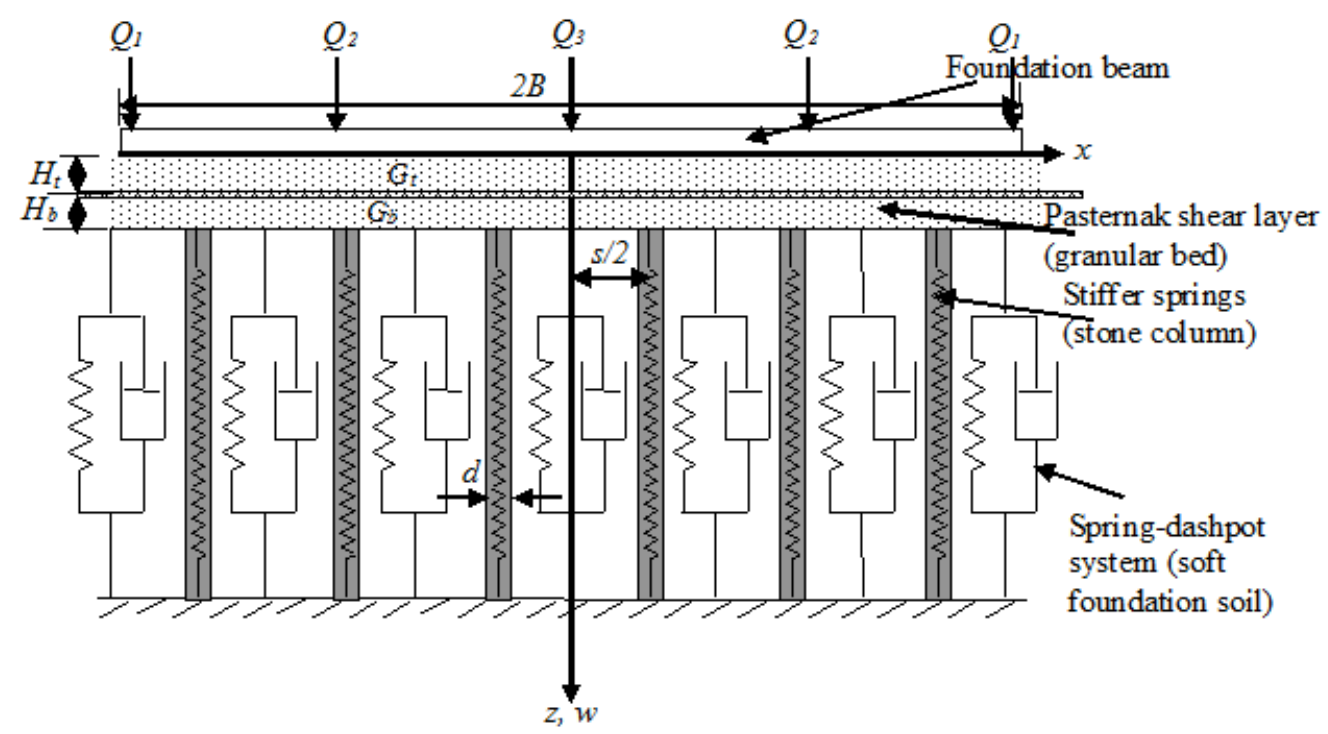

Figure 2 Idealization of proposed problem

Considering the bending of beam subjected to external load intensity, $p$, the governing equation can be written as:

$$
E I \frac{d^{4} w}{d x^{4}}+q=p
$$

Combining the above equations yields the governing differential equations of the soil-foundation system below the footing.

\subsection{Non-dimensionalization of proposed model}

The governing differential equations have been nondimensionalized using the following parameters:

$\mathrm{X}=\mathrm{x} / \mathrm{B}, \mathrm{W}=\mathrm{w} / \mathrm{B}, \mathrm{H}_{\mathrm{t}}{ }^{*}=\mathrm{H}_{\mathrm{t}} / \mathrm{B}, \mathrm{H}_{\mathrm{b}}{ }^{*}=\mathrm{H}_{\mathrm{b}} / \mathrm{B}, \mathrm{E}_{\mathrm{g}}{ }^{*}=\mathrm{E}_{\mathrm{g}} / \mathrm{k}_{\mathrm{so}} \mathrm{B}^{2}, \mathrm{q}^{*}=\mathrm{q} / \mathrm{k}_{\mathrm{so}} \mathrm{B}, \mathrm{p}^{*}=\mathrm{p} / \mathrm{k}_{\mathrm{so}} \mathrm{B}, \mathrm{qu}_{\mathrm{u}}{ }^{*}=\mathrm{q}_{\mathrm{u}} / \mathrm{k}_{\mathrm{so}} \mathrm{B}, \mathrm{q}_{\mathrm{cu}}{ }^{*}$ $=\mathrm{q}_{\mathrm{cu}} / \mathrm{k}_{\mathrm{co}} \mathrm{B}=\mathrm{q}_{\mathrm{cu}} / \alpha \mathrm{k}_{\mathrm{so}} \mathrm{B}, \tau_{\mathrm{ut}}{ }^{*}=\tau_{\mathrm{ut}} \mathrm{H}_{\mathrm{t}} / \mathrm{k}_{\mathrm{so}} \mathrm{B}^{2}, \tau_{\mathrm{ub}}{ }^{*}=\tau_{\mathrm{ub}} \mathrm{H}_{\mathrm{b}} / \mathrm{k}_{\mathrm{so}} \mathrm{B}^{2}, \mathrm{~T}^{*}=\mathrm{T} / \mathrm{k}_{\mathrm{so}} \mathrm{B}^{2}, \mathrm{I}^{*}=\mathrm{E} \mathrm{I} / \mathrm{k}_{\mathrm{so}} \mathrm{B}^{4}, \mathrm{G}_{\mathrm{to}}{ }^{*}$ $=\mathrm{G}_{\mathrm{to}} \mathrm{H}_{\mathrm{t}} / \mathrm{k}_{\mathrm{so}} \mathrm{B}^{2}, \mathrm{G}_{\mathrm{bo}}{ }^{*}=\mathrm{G}_{\mathrm{bo}} \mathrm{H}_{\mathrm{t}} / \mathrm{k}_{\mathrm{so}} \mathrm{B}^{2}, \mathrm{Q}_{1}{ }^{*}=\mathrm{Q}_{2}{ }^{*}=\mathrm{Q}_{3}{ }^{*}=\mathrm{Q}^{*}=\mathrm{Q} / \mathrm{k}_{\mathrm{so}} \mathrm{B}^{2}$ and $\alpha=\mathrm{k}_{\mathrm{co}} / \mathrm{k}_{\mathrm{so}}$.

The equations below the footing have been written in nondimensional form as follows:

$$
\begin{aligned}
& q^{*}=\frac{W}{U\left[1+\left(W / q_{u}^{*}\right)\right]^{-}} T^{*} \cos ^{3} \theta \frac{d^{2} W}{d X^{2}}-\sin \theta \frac{d T^{*}}{d X}-\left(G_{t}^{1^{*}}+G_{b}^{1^{*}}\right) \frac{d^{2} W}{d X^{2}}, \text { within soft soil region (5a) }
\end{aligned}
$$

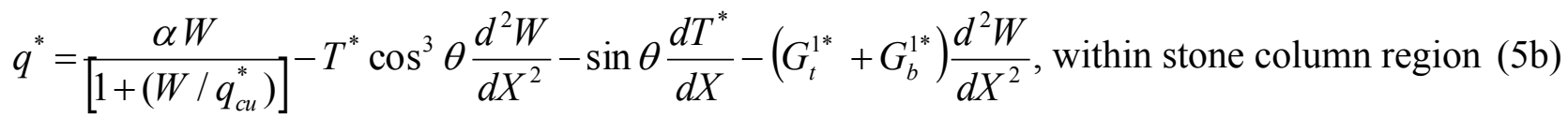

$$
\begin{aligned}
& \frac{d^{2} T^{*}}{d X^{2}}=\sin \theta \cos \theta \frac{d^{2} W}{d X^{2}} \frac{d T^{*}}{d X}+\frac{1}{\cos \theta}\left(\frac{G_{t}^{o^{*}}}{H_{t}^{* 2}}+\frac{G_{b}^{o^{*}}}{H_{b}^{* 2}}\right)\left[\sqrt{\left(\frac{T^{*}}{E_{g}^{*}}+1\right)^{2}-\left(\frac{d W}{d X}\right)^{2}}-1\right] \\
& +\frac{H_{b}^{*}}{H_{t}^{*}}\left(\frac{G_{t}^{o^{*}}}{\tau_{u b}^{*}}-\frac{G_{b}^{o^{*}}}{\tau_{u t}^{*}} \frac{G_{t o}^{*}}{G_{b o}^{*}} \frac{G_{t}^{1^{*}}}{G_{b}^{1^{*}}}\right) \frac{G_{b}^{o^{*}}}{\left(G_{t}^{o^{*}} \frac{H_{b}^{*}}{H_{t}^{*}}+G_{b}^{o^{*}} \frac{H_{t}^{*}}{H_{b}^{*}}\right)} \frac{d^{2} W}{d X^{2}} \frac{d T^{*}}{d X}
\end{aligned}
$$

and

$$
\frac{d^{4} W}{d X^{4}}+\frac{q^{*}}{I^{*}}-\frac{p^{*}}{I^{*}}=0
$$




\subsection{Boundary conditions}

Due to symmetry, half of the spatial domain has been considered in the analysis. The boundary conditions have been written as follows:

$$
\begin{gathered}
\text { At } x=0, \frac{d w}{d x}=0 ;-E I \frac{d^{3} w}{d x^{3}}=\frac{Q}{2} \text { and } \frac{d T}{d x}=0 \text { (8) } \\
\text { At } x=B, \frac{d^{2} w}{d x^{2}}=0 ;-E I \frac{d^{3} w}{d x^{3}}=-Q-\left(T \cos ^{3} \theta+G_{t}^{\prime} H_{t}+G_{b}^{\prime} H_{b}\right) \frac{d w}{d x}-T \sin \theta \text { (9) } \\
\text { At } x=L, \frac{d w}{d x}=0 \text { and } T=0 \text { (10) }
\end{gathered}
$$

2.4 Solution methodology and convergence criterion

A finite difference scheme has been adopted to obtain the solution of the soil-foundation system. The governing differential equations along with boundary conditions have been written in finite difference form and solution has been obtained by Gauss Siedel iterative scheme. The solution has been obtained with convergence criteria as

$$
\left|\frac{W_{i}^{k}-W_{i}^{k-1}}{W_{i}^{k}}\right|<\varepsilon \text { and }\left|\frac{T_{i}^{*_{k}}-T_{i}^{*_{k-1}}}{T_{i}^{* k}}\right|<\varepsilon
$$

for all nodes $i$, where $k$ and $k$-1 are the present and previous iterations respectively and $\varepsilon$ is the specified tolerance which has been considered to be $10^{-8}$ in the present study.

\subsection{RESULTS AND DISCUSSION}

The above formulation has been programmed in $\mathrm{C}$ language and solution obtained by a finite difference scheme. Due to symmetry, only half of the spatial domain has been considered. It was observed that results corresponding to finite difference mesh with 401 and 501 nodes vary negligibly. In view of this, the whole spatial domain was discretized with 401 nodes for all parametric studies. After obtaining the deflection of the footing, bending moment and shear force have been obtained by taking appropriate derivative of the deflection.

\subsection{Validation}

Before the conduct of the detailed parametric study, the proposed mathematical model and developed computer program has been validated by comparing the results to those from Deb et al. [10]. A parameter, $\alpha$ was considered and defined as

$$
\alpha=\frac{\left(1+v_{s}\right)\left(1-2 v_{s}\right)}{\left(1+v_{c}\right)\left(1-2 v_{c}\right)} \frac{E_{c}}{E_{s}}=\frac{k_{c o}}{k_{s o}}
$$

where $\left(E_{s}, v_{s}\right)$ and $\left(E_{c}, v_{c}\right)$ are elastic properties with respect to soil and the stone columns respectively. For the validation purpose, the input parameters have been considered as $v_{s}=v_{c}=0.3, G_{t o}{ }^{*}=G_{b o}{ }^{*}=$ $0.1, H_{t}{ }^{*}=H_{b}{ }^{*}=0.25, q^{*}=0.8, q_{u}{ }^{*}=10, E_{g}{ }^{*}=20, \tau_{u}{ }^{*}=10, U=100 \%$. Results from the present study for these parameters have been presented along with the results from Deb et al. [10] in Fig. 3. Perfect match between these results can be observed from Fig. 3 which validated the proposed model. 


\subsection{Range of values of input parameters}

The range of values of input parameters considered in the present study has been mentioned in Table 1 in dimensional form $[7,15,16,17,18]$. These have been non-dimensionalized employing the abovementioned parameters and used in the parametric study.

\subsection{Influence of applied loads}

The variation of deflection of combined footing along its length has been depicted in Fig. 4 for five different load levels. Further, the comparison has been made with inextensible geosynthetic reinforcement [11]. The input parameters have been considered as $I^{*}=1.5 \times 10^{-4}, G_{t o} *=G_{b o} *=9.8 \times 10^{-}$ ${ }^{5}, d / B=0.05, s / d=2.5, q_{u}^{*}=4 \times 10^{-4}, q_{c u} *=1.5 \times 10^{-4}, \tau_{u t} *=\tau_{u b} *=1.05 \times 10^{-6}, \alpha=10, U=90 \%$. The deflection has not been found to be influenced by type of geosynthetics significantly. However, at higher load levels some marginal effect has been observed. The normalized maximum deflection has been found to reduce by $92 \%$ as the normalized load reduces from $2.25 \times 10^{-4}$ to $1.0 \times 10^{-4}$.

The tension mobilized in the geosynthetic layer has been found to be significantly affected by type of geosynthetics (Fig. 5). In the case of extensible geosynthetics, the order of mobilized tension is much less than in the case of inextensible geosynthetic layer. The reduction in normalized tension mobilized in geosynthetics has been found to be about $97 \%$ for the corresponding reduction in normalized applied load from $2.25 \times 10^{-4}$ to $1.0 \times 10^{-4}$. The variation of normalized bending moment in the combined footing along the length of footing has been presented in Fig. 6 for various load levels.

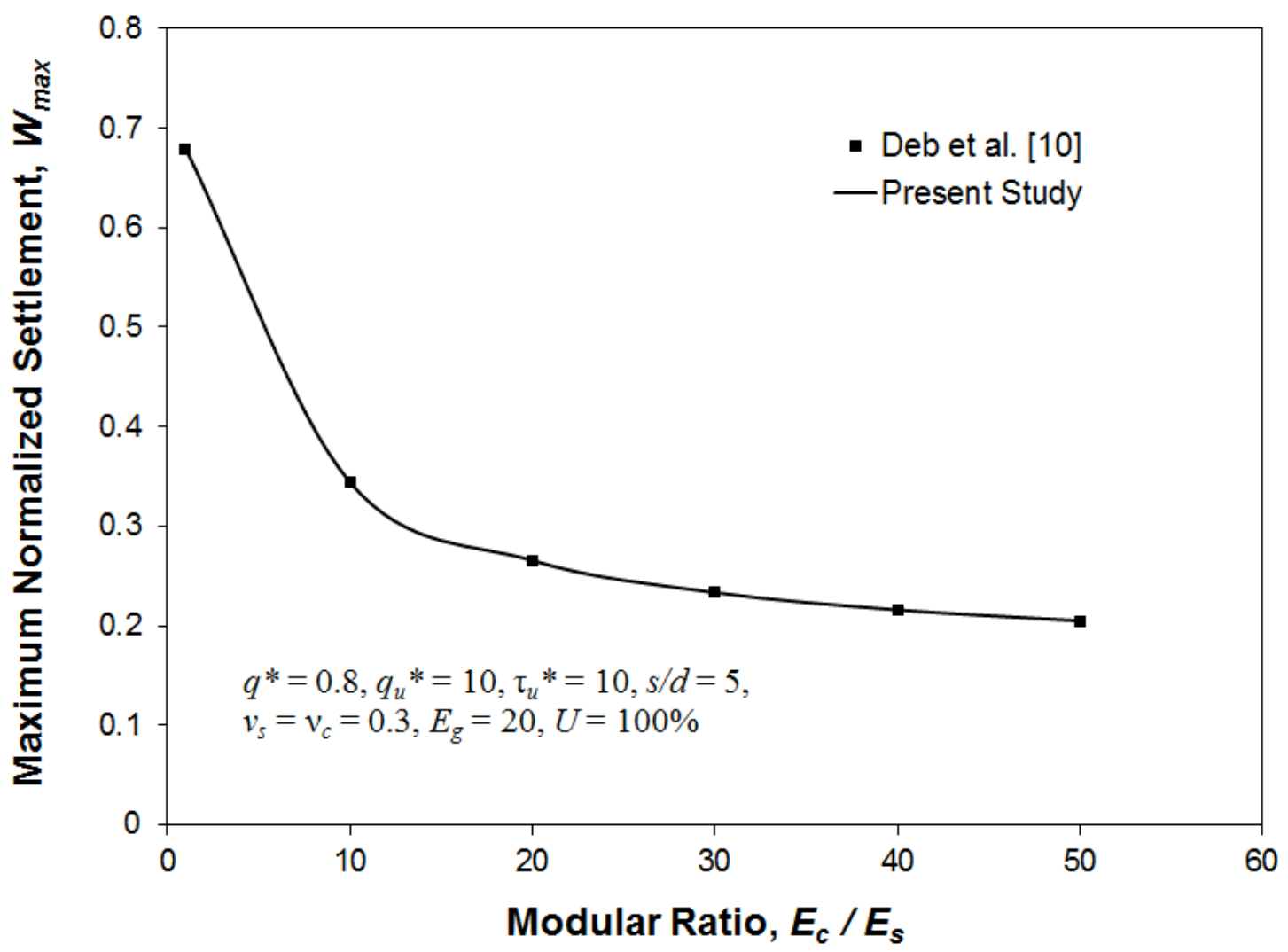

Figure 3 Maximum normalized settlement: validation

\subsection{Influence of flexural rigidity of footing}

To study the influence of flexural rigidity, $E I$ of the footing, the values of input parameters have been taken as $Q^{*}=2.0 \times 10^{-4}, G_{t o} *=G_{b o} *=9.8 \times 10^{-5}, d / B=0.05, s / d=2.5, q_{u}^{*}=4 \times 10^{-4}, q_{c u} *=6 \times 10^{-5}$, $E_{g}{ }^{*}=0.025, \tau_{u t} *=\tau_{u b} *=1.05 \times 10^{-6}, \alpha=25, U=90 \%$. Figures 7 and 8 show the influence of flexural rigidity on deflection of the footing and mobilized tension in geosynthetics respectively. The maximum 
normalized deflection has been found to reduce by $88 \%$ as the normalized flexural rigidity increases from $1.5 \times 10^{-4}$ to $2.0 \times 10^{-3}$ and the corresponding reduction in tension mobilized in geosynthetic has been found to be $96 \%$. As the flexural rigidity of the footing increases, the footing exhibits resistance to deformation and bending and therefore the deflection of footing and tension mobilized in geosynthetic is lesser and more uniform.

Table 1 Range of values of input parameters considered for parametric study

\begin{tabular}{ccc}
\hline Parameter & Symbol (unit) & Range of values \\
\hline Applied load & $Q(\mathrm{kN})$ & $100-300$ \\
\hline Flexural rigidity of footing & $E I\left(\mathrm{MN}-\mathrm{m}^{2}\right)$ & $15-200$ \\
\hline Half-length of footing & $B(\mathrm{~m})$ & 10.0 \\
\hline Thickness of granular fill layer & $H(\mathrm{~m})$ & 0.3 \\
\hline Diameter of stone columns & $d(\mathrm{~m})$ & $0.2-0.4$ \\
\hline Initial modulus of subgrade reaction for soft foundation soil & $k_{s o}\left(\mathrm{MN} / \mathrm{m}^{2} / \mathrm{m}\right)$ & $2.5-4[15]$ \\
\hline Initial shear modulus of granular fill & $G_{o}\left(\mathrm{kN} / \mathrm{m}^{2}\right)$ & $652.4[16]$ \\
\hline Ultimate bearing resistance of soft foundation soil & $q_{u}\left(\mathrm{kN} / \mathrm{m}^{2}\right)$ & $20-60$ \\
\hline Ultimate bearing resistance of stone column & $q_{c u}\left(\mathrm{kN} / \mathrm{m}^{2}\right)$ & $100-200$ \\
\hline Ultimate shear resistance of granular fill layer & $\tau_{u}\left(\mathrm{kN} / \mathrm{m}^{2}\right)$ & $4-10$ \\
\hline Tensile stiffness of geosynthetics & $E_{g}\left(\mathrm{MN} / \mathrm{m}^{2}\right)[7]$ & $15-35$ \\
\hline Relative stiffness of stone column & $\alpha$ & $10-100$ \\
\hline Average degree of consolidation & $U$ & $40-100 \%$ \\
\hline
\end{tabular}

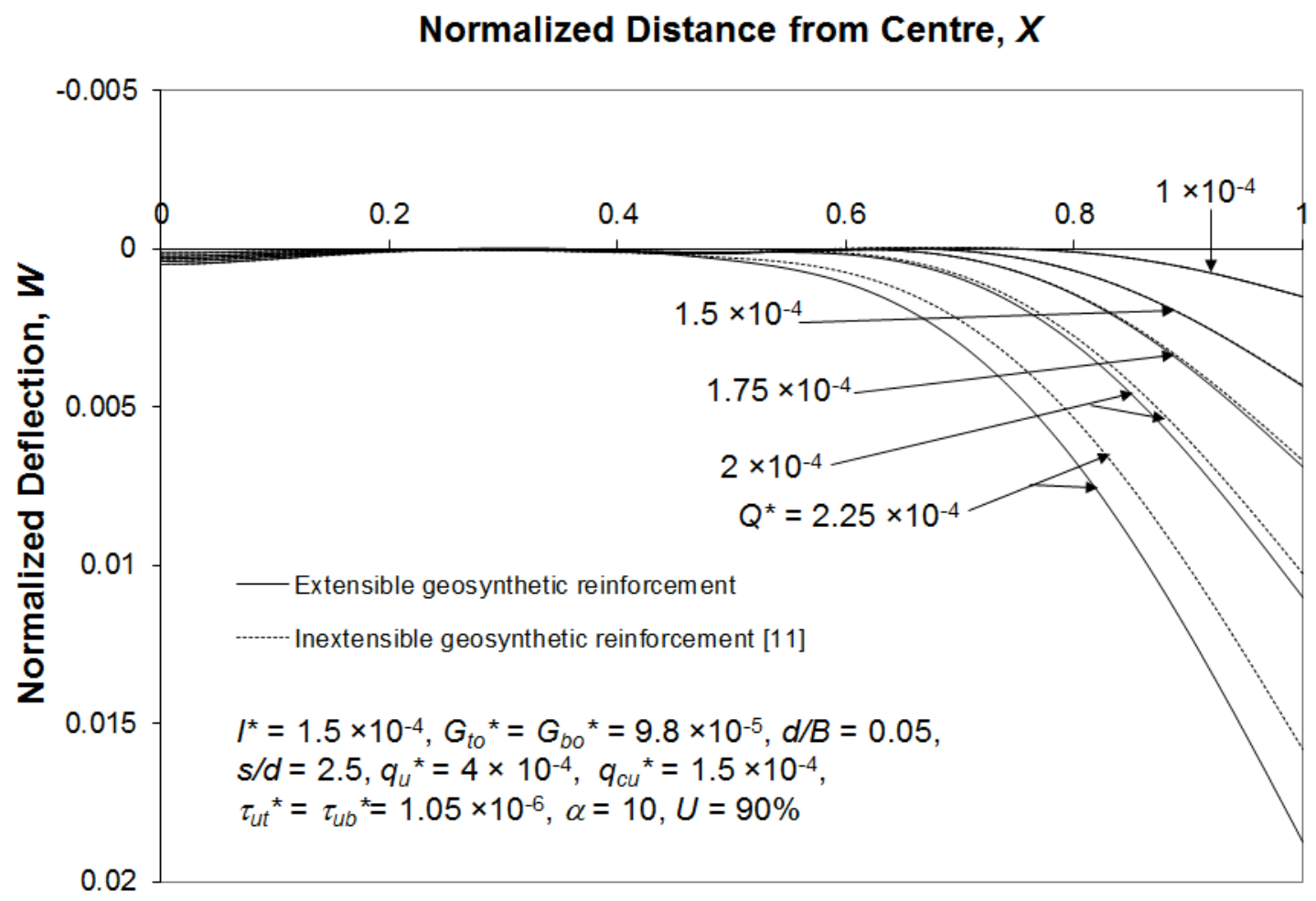

Figure 4 Variation of normalized deflection of combined footing: effect of applied load. 


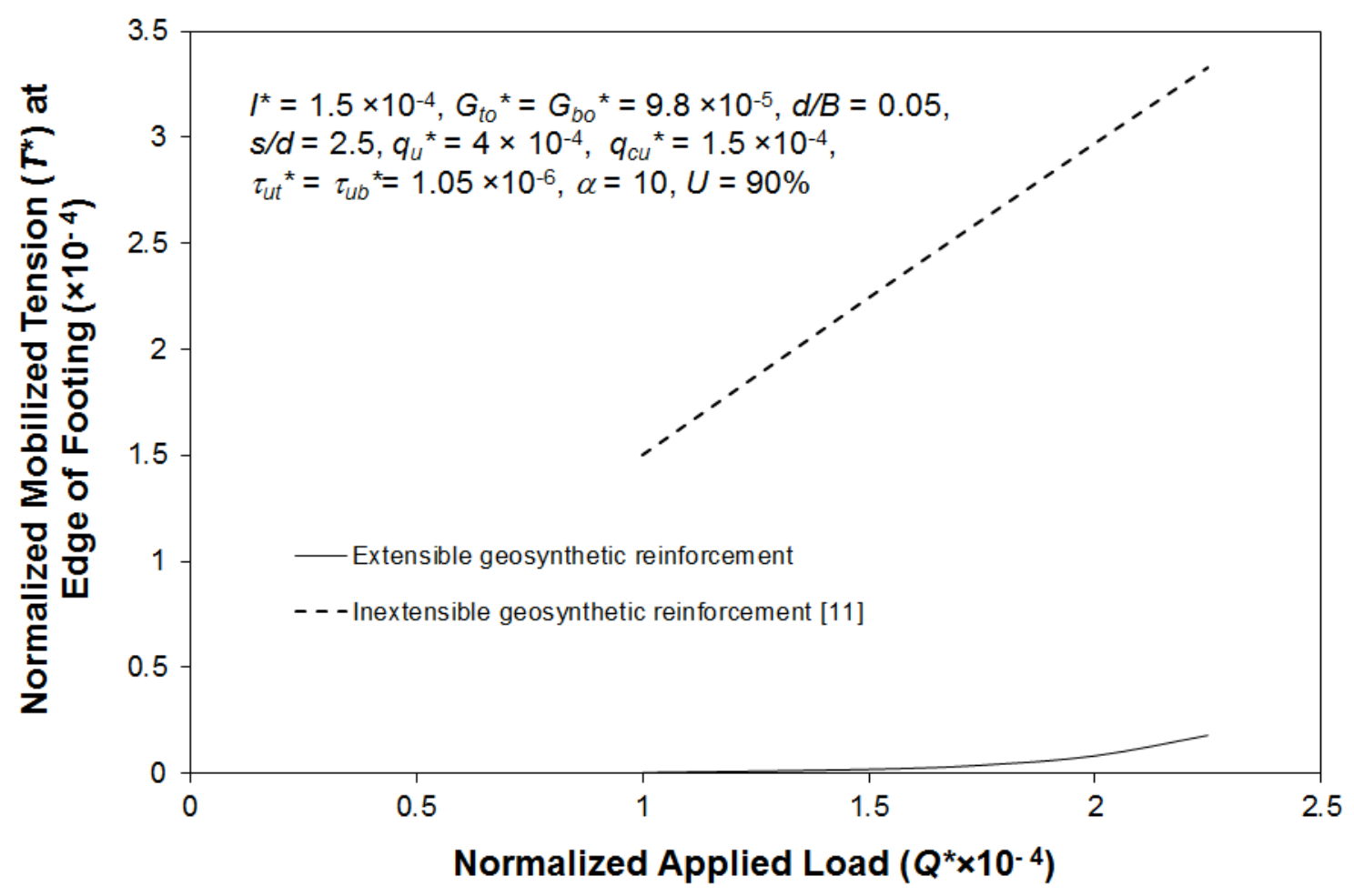

Figure 5 Variation of maximum normalized tension mobilized in geosynthetic: effect of applied load

\subsection{Influence of configuration of stone columns}

This section presents the influence of diameter and spacing of the stone columns on response of the soilfooting system for the input parameters. The normalized diameter of stone columns $(d / B)$ has been varied from 0.02 to 0.1 while the variation in spacing to diameter ratio $(s / d)$ has been considered as $2-$ 4. Figures 9 and 10 exhibit the influence of normalized diameter on deflection of the footing and tension mobilized in the geosynthetic layer respectively. About $37 \%$ increase in maximum normalized deflection and $64 \%$ increase in mobilized tenion has been observed as normalized diameter increases from 0.02 to 0.1 . For lesser value of parameter $d / B$, more number of stone columns exist below the footing and therefore the deflection and mobilized tension is less.

Figure 11 depicts the effect of $s / d$ on deflection of the footing for the input parameters as mentioned in the figure. There will be a lesser number of stone columns beneath the footings for higher values of the parameter $s / d$ and therefore larger deflection has been observed for higher values of spacing to diameter ratio of stone columns. An optimum value of $s / d$ can be observed as $2.5-3$. Typical bending moment variation along the length of footing has been presented in Fig. 12 for different values of parameter $s / d$.

\subsection{Influence of tensile stiffness of geosynthetic layer}

Tensile stiffness of the geosynthetic layer has no influence on response of the footing. However, it significantly affects the tension mobilized in the geosynthetic layer. The variation of maximum normalized mobilized tension with normalized tensile stiffness of geosynthetic has been presented in Fig. 13. As expected, a reduction of about $34 \%$ is observed corresponding to the reduction in parameter $E_{g}{ }^{*}$ from 0.035 to 0.015 . 


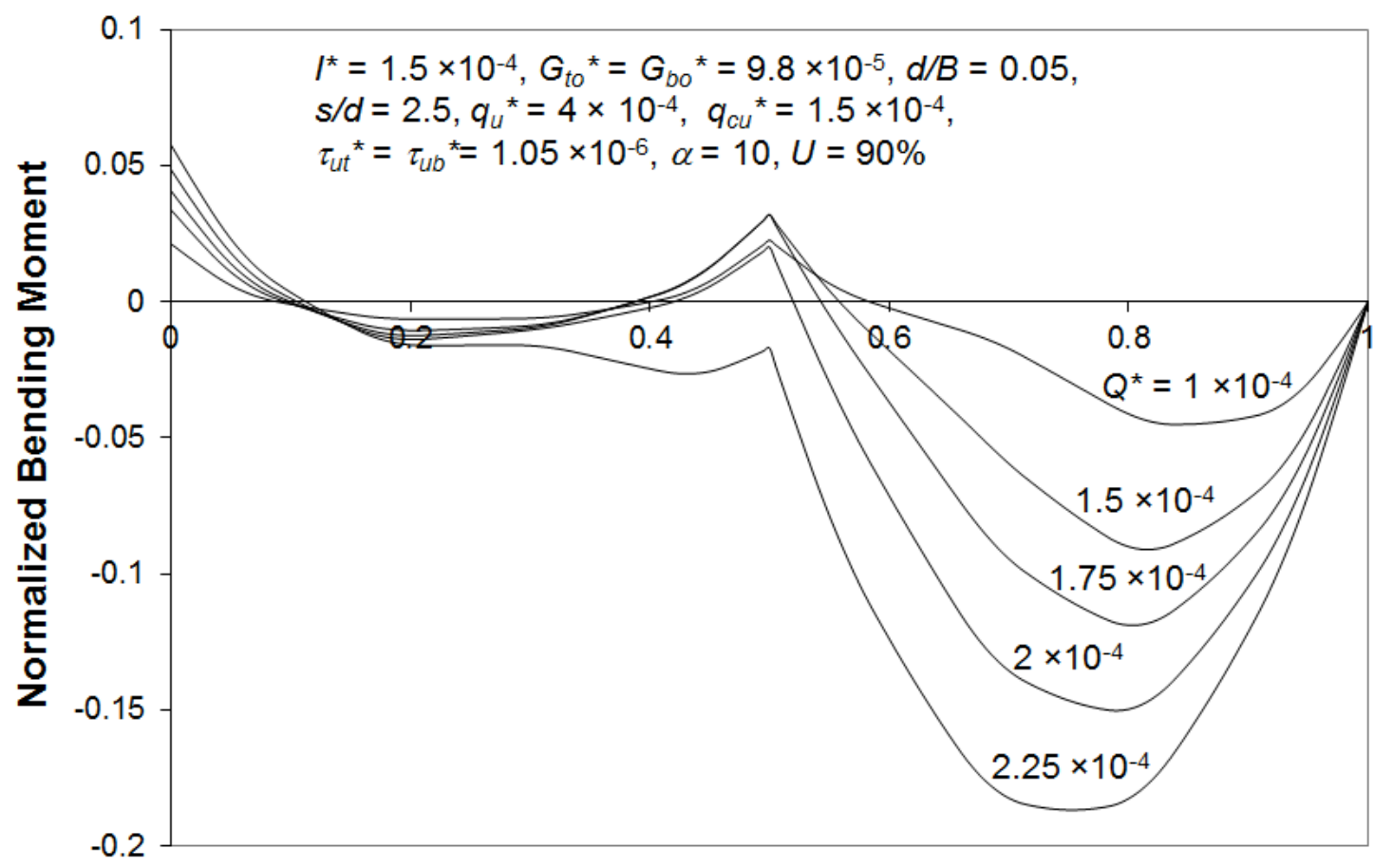

Normalized Distance from Centre, $X$

Figure 6 Variation of normalized bending moment in combined footing: effect of applied load

Normalized Distance from Centre, $X$

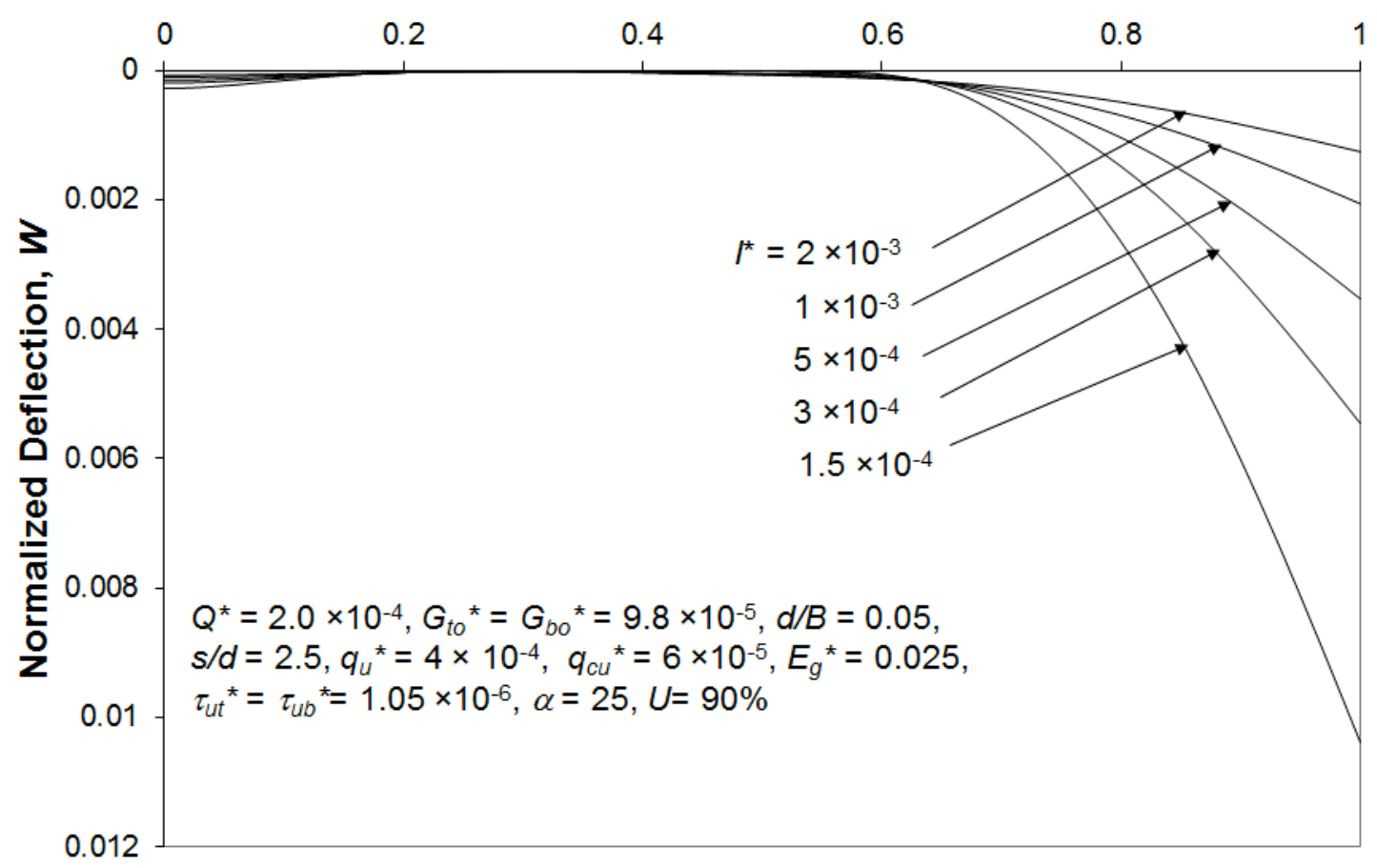

Figure 7 Variation of normalized deflection of combined footing: effect of flexural rigidity 


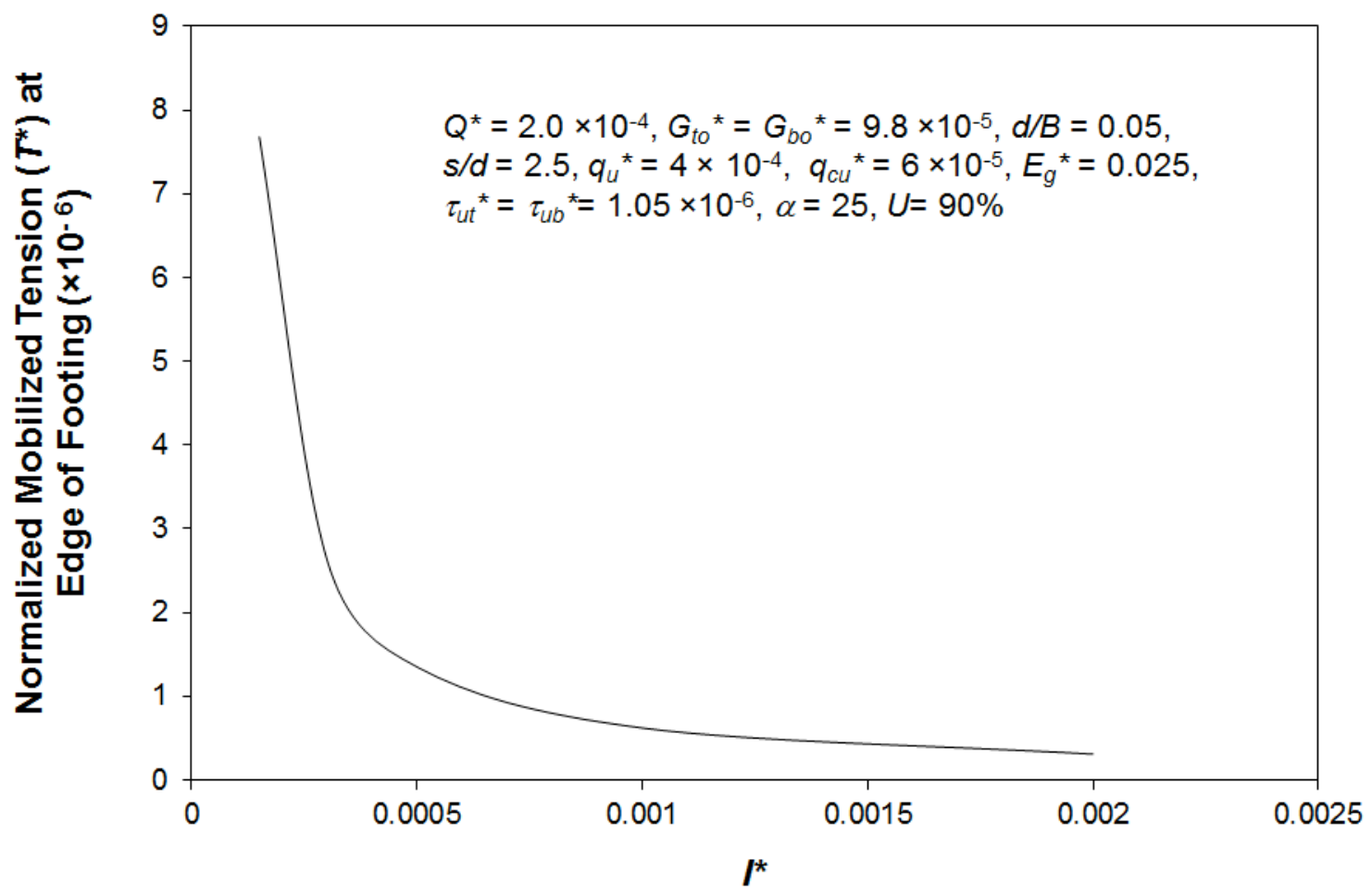

Figure 8 Variation of maximum normalized tension mobilized in geosynthetic: effect of flexural rigidity

Normalized Distance from Centre, $X$

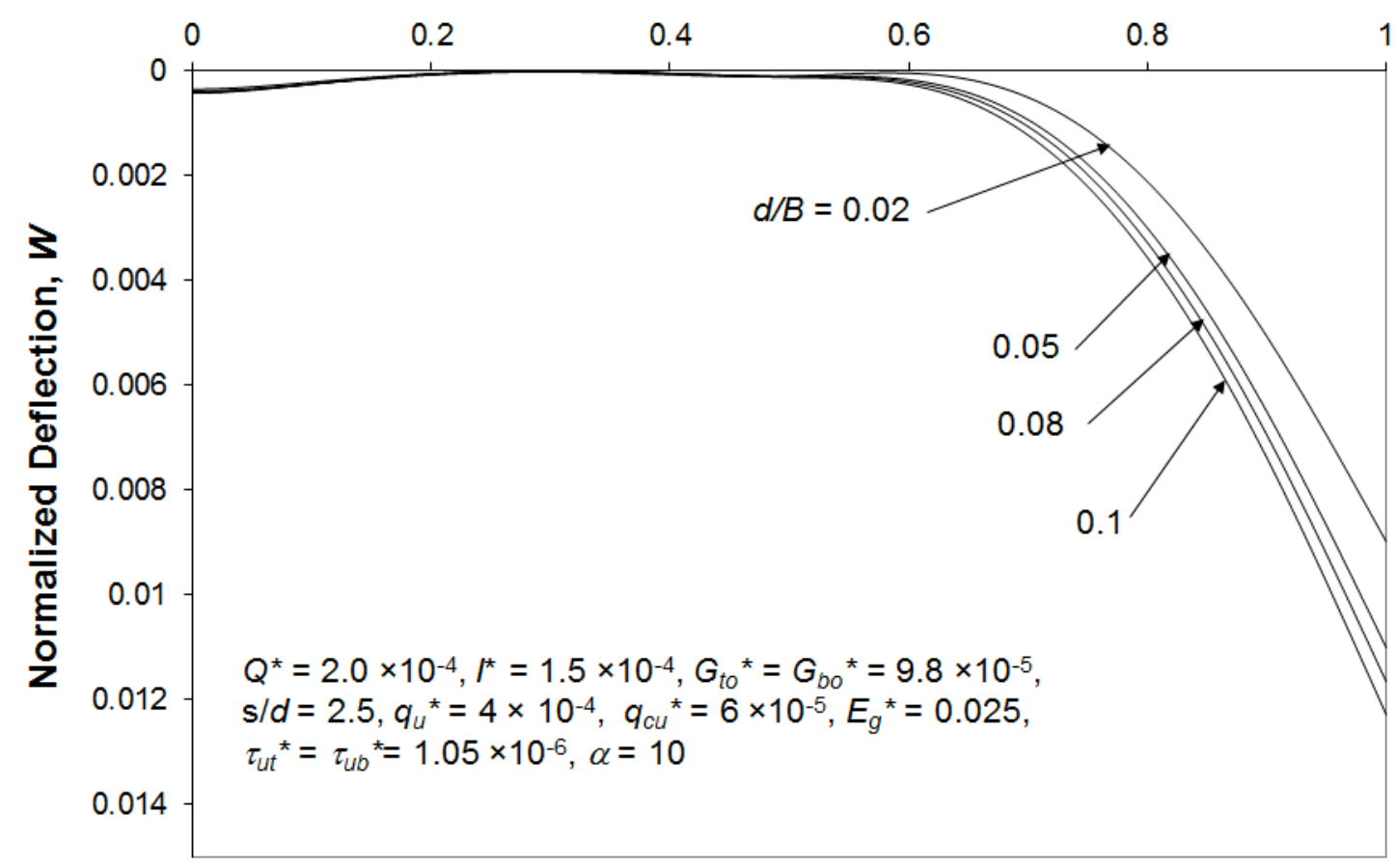

Figure 9 Variation of normalized deflection of combined footing: effect of parameter, $d / B$. 


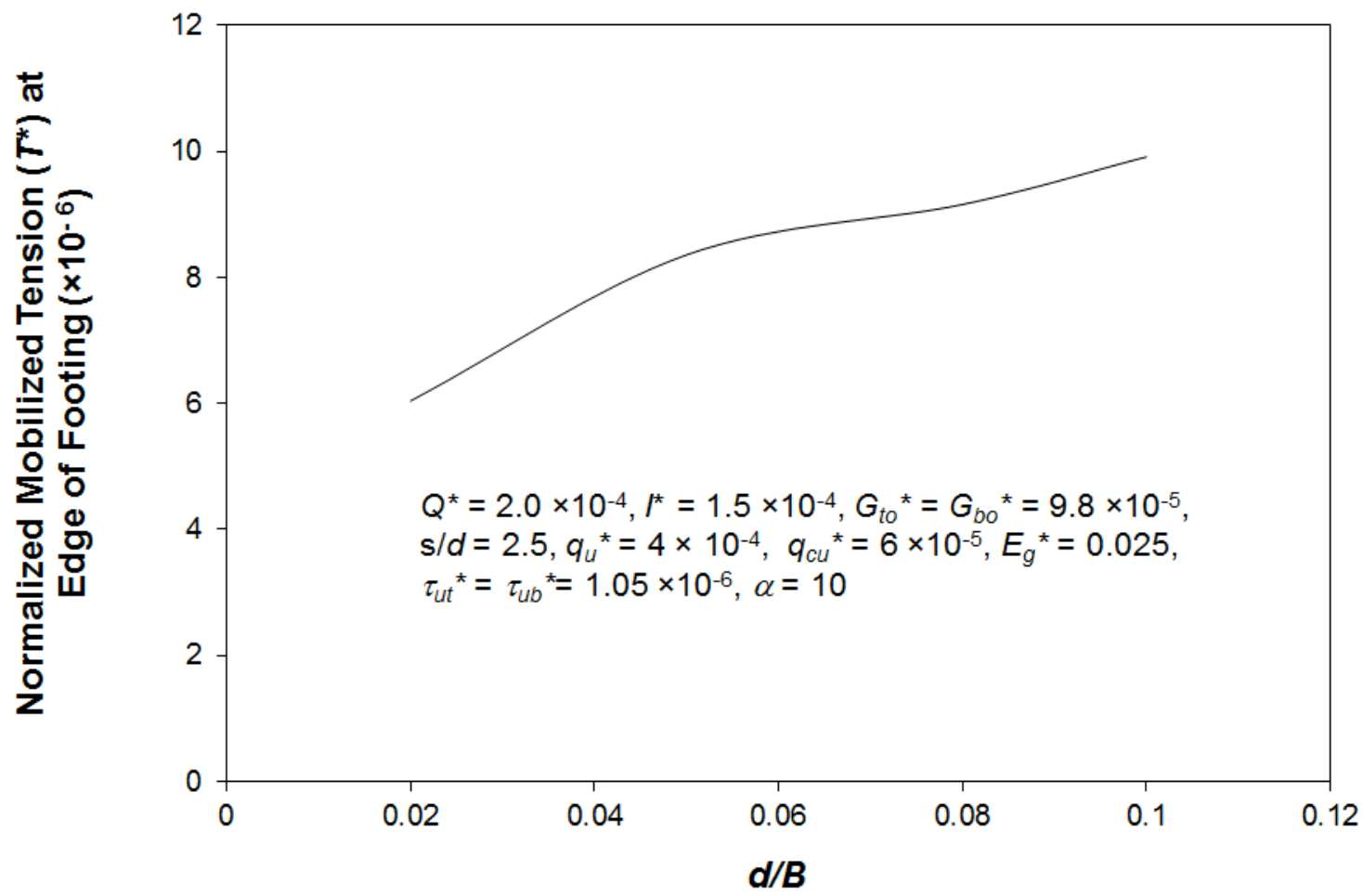

Figure 10 Variation of maximum normalized tension mobilized in geosynthetic: effect of parameter, $d / B$

Normalized Distance from Centre, $X$

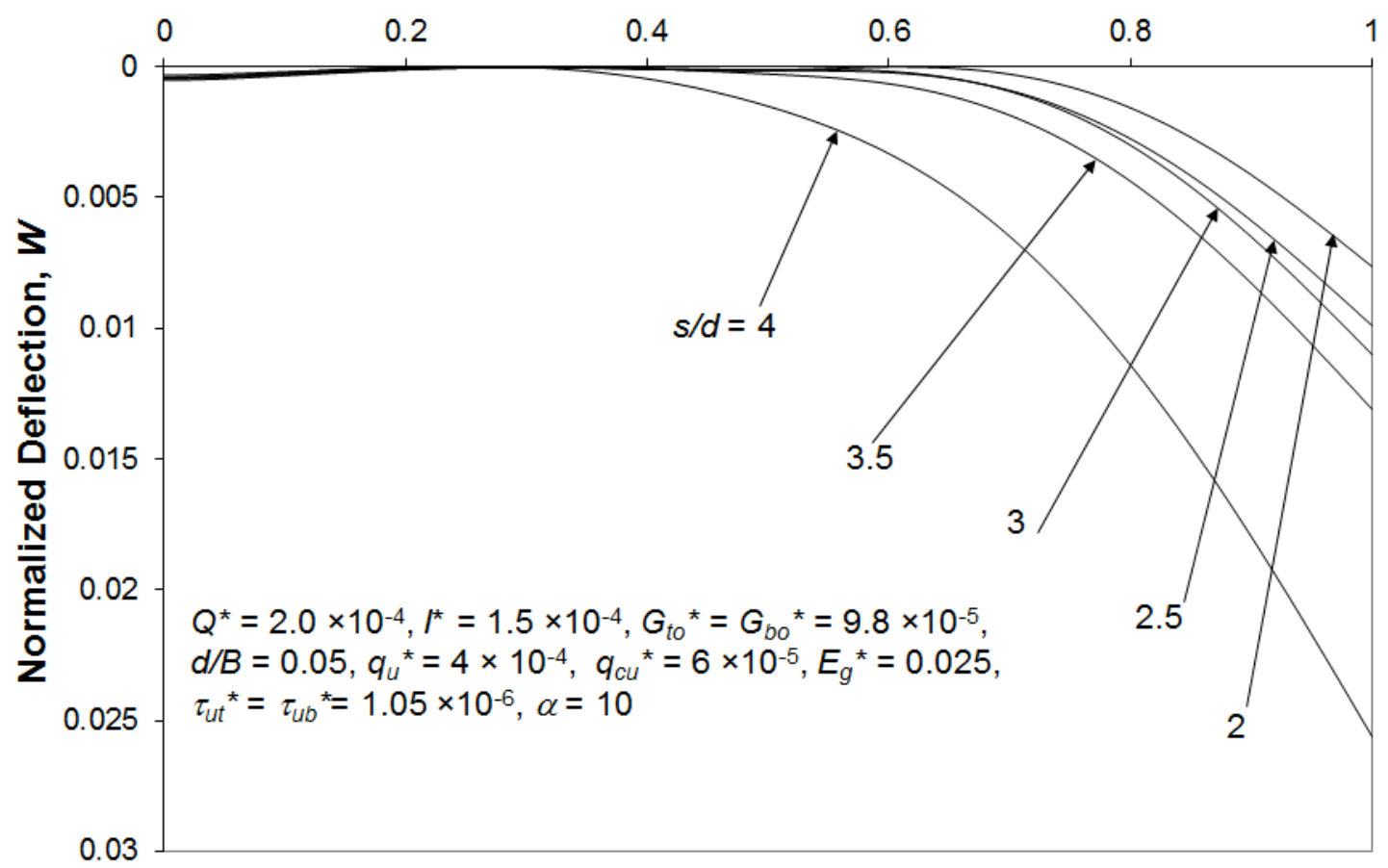

Figure 11 Variation of normalized deflection of combined footing: effect of parameter, $s / d$ 


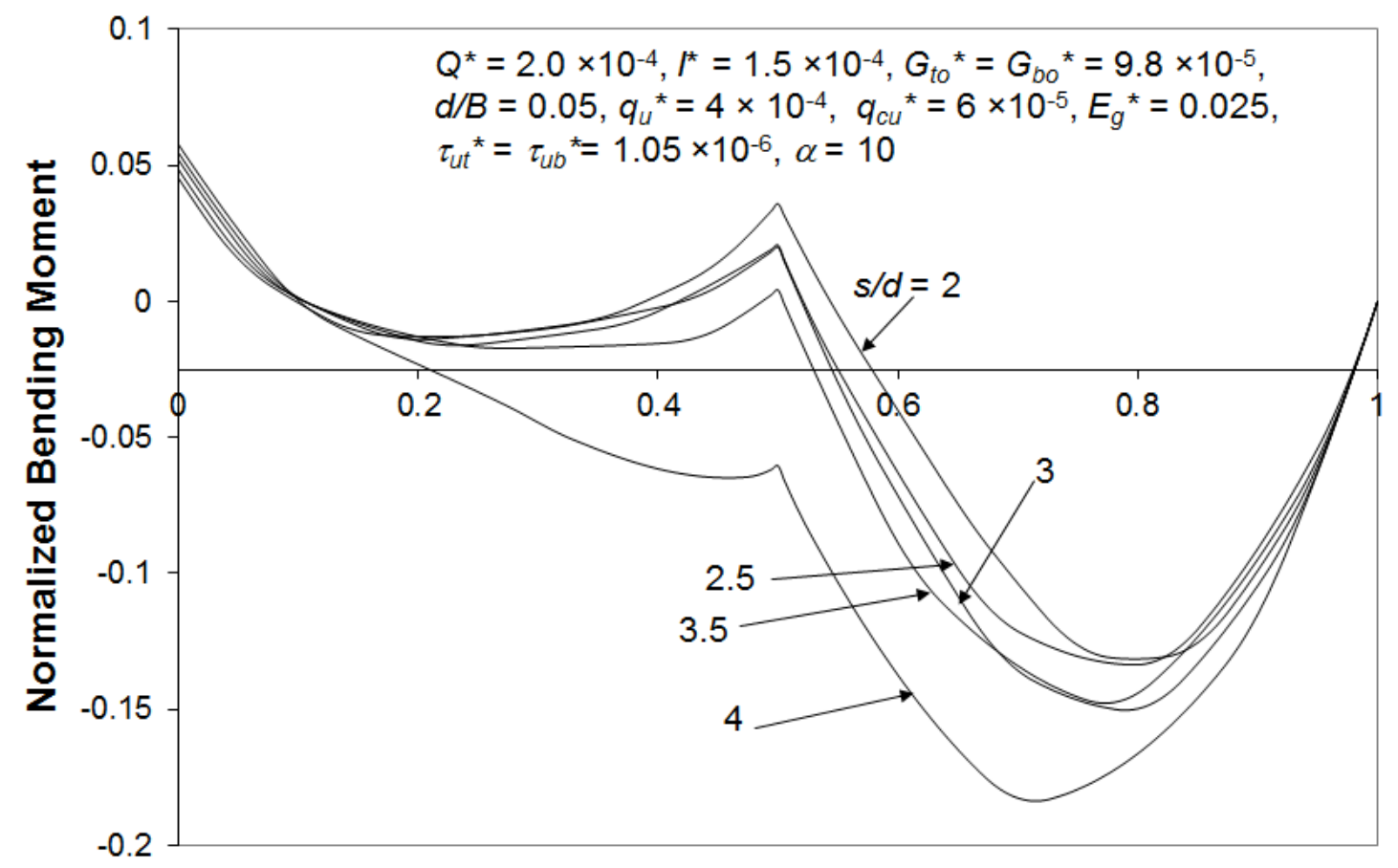

Normalized Distance from Centre, $X$

Figure 12 Variation of normalized bending moment in combined footing: effect of parameter, s/d

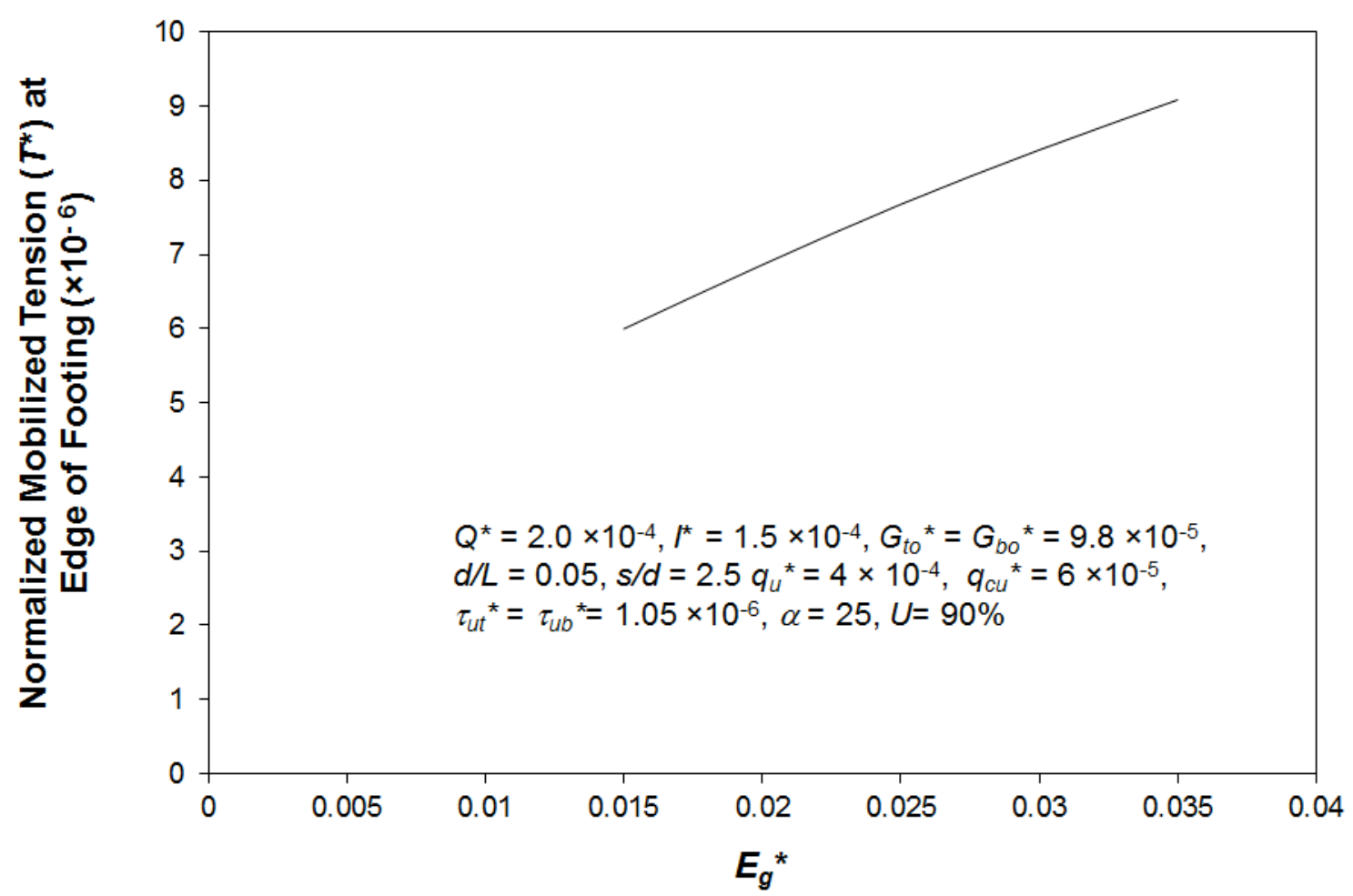

Figure 13 Variation of maximum normalized tension mobilized in geosynthetic: effect of tensile stiffness of geosynthetic

3.7 Influence of ultimate bearing resistance of foundation soil $\left(q_{u}{ }^{*}\right)$ and stone columns $\left(q_{c u}{ }^{*}\right)$

An increase in deflection of the footing is expected due to reduction in the parameters $q_{u}{ }^{*}$ and $q_{c u}{ }^{*}$. The same has been observed during the analysis and has been presented in Figs. 14 and 15. A reduction of about $54 \%$ and $62 \%$ has been observed in maximum normalized deflection of the footing corresponding to a respective reduction in $q_{u}{ }^{*}$ from $6 \times 10^{-4}$ to $2 \times 10^{-4}$ and in $q_{c u}{ }^{*}$ from $8 \times 10^{-5}$ to $5 \times 10^{-5}$. The tension mobilized in geosynthetic layer has also been significantly affected by any variation in these two 
parameters, $q_{u}{ }^{*}$ and $q_{c u}{ }^{*}$.

\section{Normalized Distance from Centre, $X$}

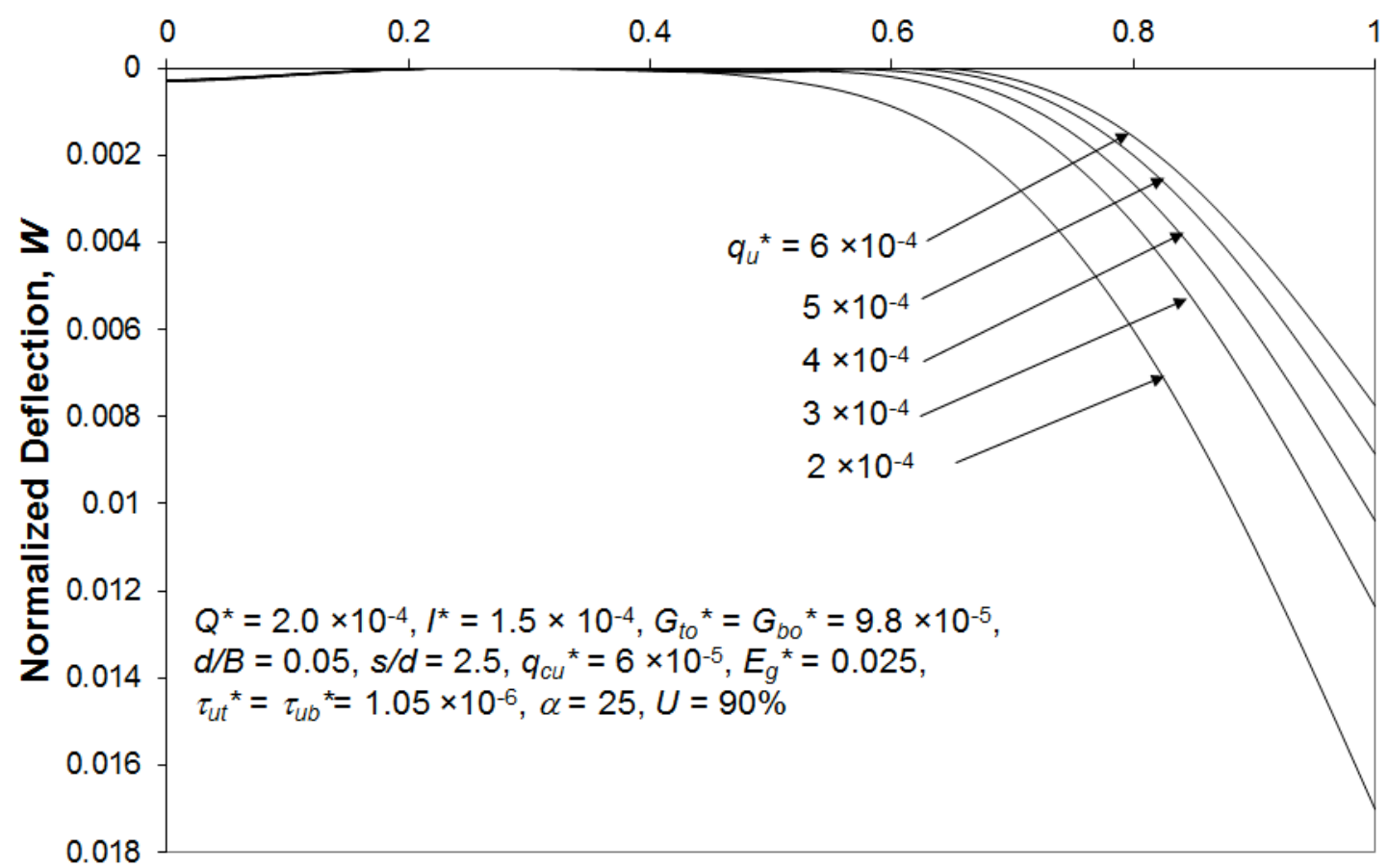

Figure 14 Variation of normalized deflection of combined footing: effect of ultimate bearing resistance of foundation soil $\left(q_{u}{ }^{*}\right)$

\section{Normalized Distance from Centre, $X$}

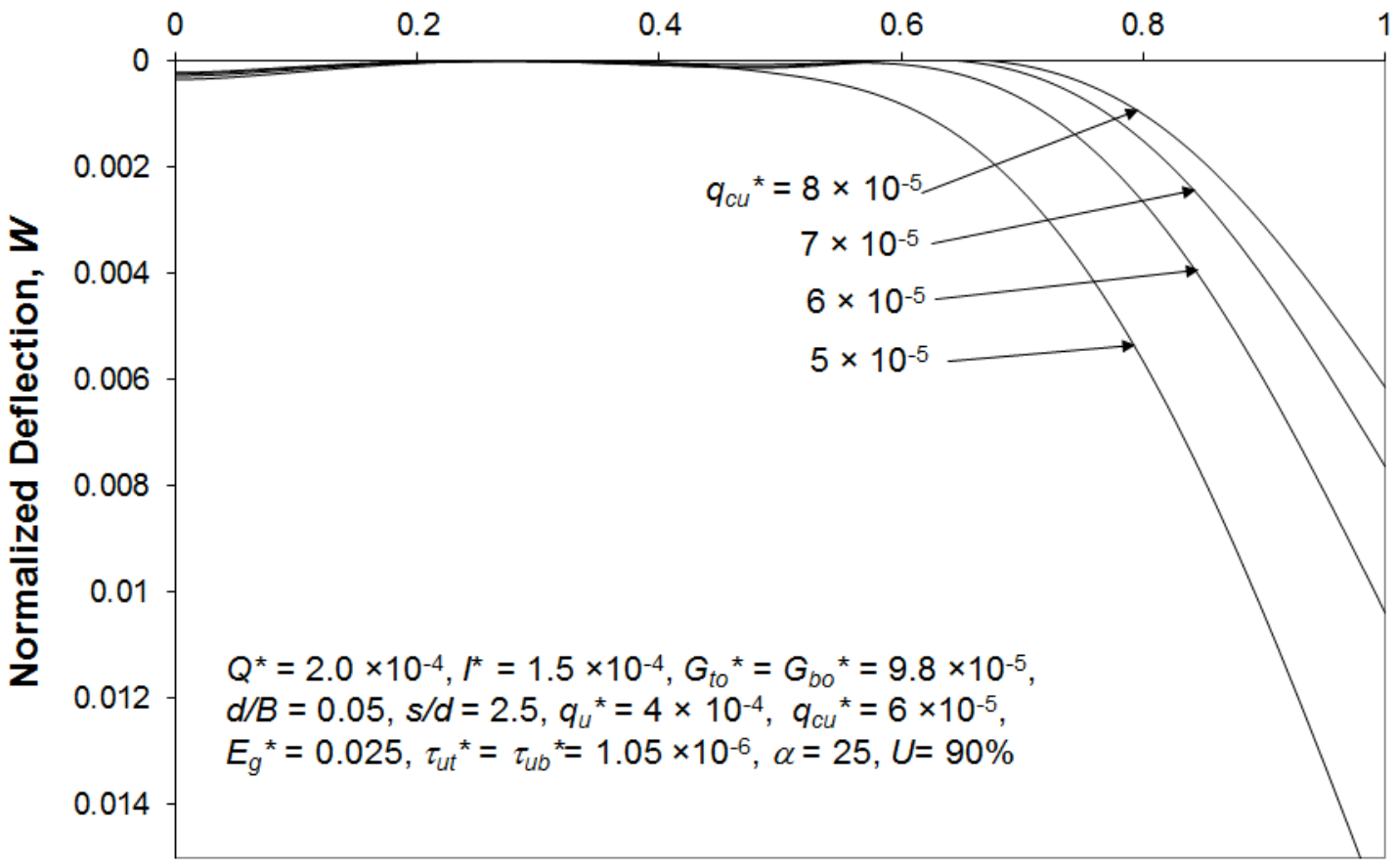

Figure 15 Variation of normalized deflection of combined footing: effect of ultimate bearing resistance of stone columns $\left(q_{c u}{ }^{*}\right)$

\subsection{Influence of degree of consolidation $(U)$}

It is well known that deflection increases with increase in degree of consolidation. This effect has been quantified with respect to the present soil-footing system. It can be observed from Fig. 16 that for the values of input parameters considered in the analysis, the maximum deflection increases by about $114 \%$ 
as degree of consolidation increases from $40 \%$ to $100 \%$. The corresponding sharp increase of $248 \%$ has been observed in maximum normalized tension mobilized in the geosynthetic layer and this variation has been depicted in Fig. 17.

\section{Normalized Distance from Centre, $X$}

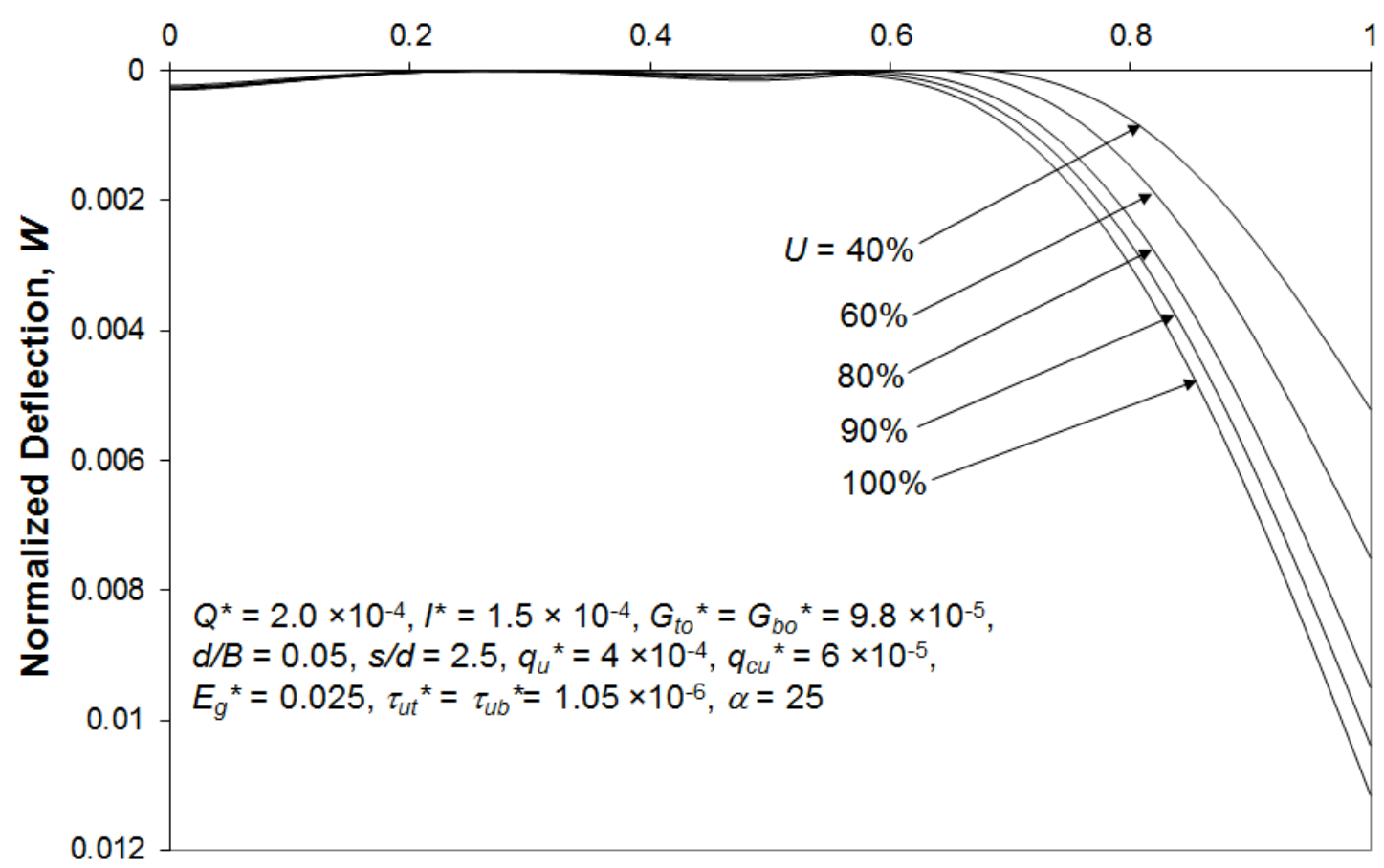

Figure 16 Variation of normalized deflection of combined footing: effect of degree of consolidation $(U)$

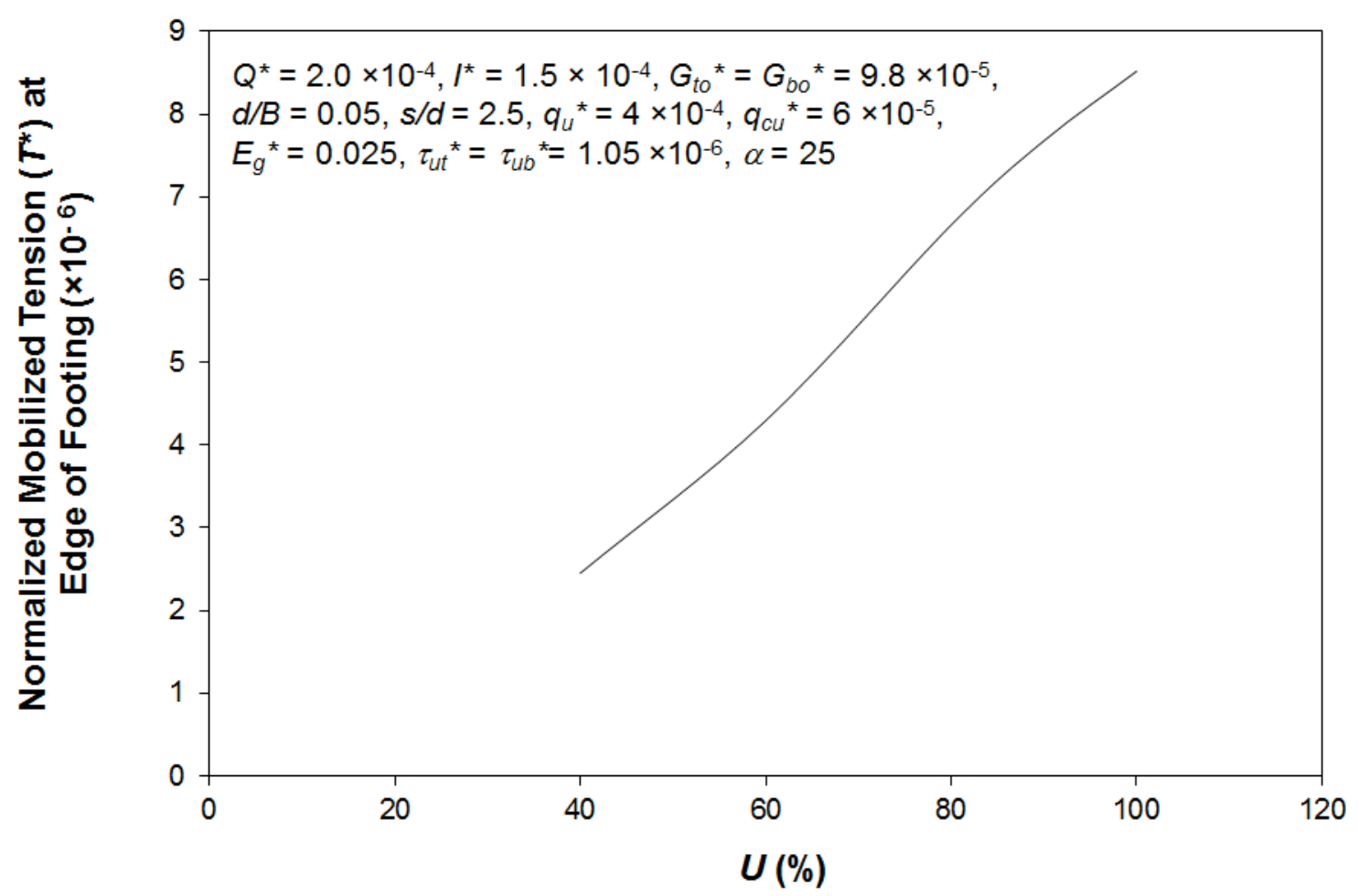

Figure 17 Variation of maximum normalized tension mobilized in geosynthetic: effect of degree of consolidation $(U)$

\subsection{CONCLUDING REMARKS}

The proposed model represented the behavior of combined footings resting on extensible geosyntheticstone column reinforced earth beds. Nonlinear behavior of foundation soil, granular fill on top of 
geosynthetic layer and stone columns have successfully been incorporated in the analysis. Results from the present study were found to be in good agreement with those existing in literature. The response of combined footing was found to be almost independent of type of geosynthetic (whether extensible or inextensible). However, response of geosynthetic in terms of tension mobilized was found to be significantly affected by type of geosynthetic. Values of tension mobilized in geosynthetic layer reduces to a large extent as the type of geosynthetic changes from inextensible to extensible. The influence of parameters like applied loads, flexural rigidity of footing, spacing and diameter of stone columns, ultimate bearing resistance of foundation soil and stone columns, tensile stiffness of geosynthetic layer and degree of consolidation have been quantified with the help of detailed parametric study for physically possible input parameters. Non-dimensional ready to use charts have been developed for response of footings in terms of its deflection and the bending moment and for response of geosynthetic in terms of tension mobilized in the geosynthetic layer. The footing can be designed as against settlement criteria employing these charts and its section modulus can be chosen accordingly. Further, appropriate selection of geosynthetics can be made with respect to its tensile stiffness.

\section{REFERENCES}

[1] Balaam, N.P. \& Booker, J.R. (1981). Analysis of Rigid Rafts Supported by Granular Piles. International Journal for Numerical and Analytical Methods in Geomechanics. 5: 379-403.

[2] Alamgir, M., Miura, N., Poorooshasb, H. B. \& Madhav,M. R. (1996). Deformation Analysis of Soft Ground Reinforced by Columnar Inclusions. Computers and Geotechnics. 18 (4): 267-290.

[3] Shahu, J. T., Madhav, M. R. \& Hayashi, S. (2000). Analysis of Soft Ground-Granular Pile-Granular Mat System. Computers and Geotechnics. 27 (1): 45-62.

[4] Madhav, M. R. \& Poorooshasb, H. B. (1988). A New Model for Geosynthetic Reinforced Soil. Computers and Geotechnics. 6 (4): 277-290.

[5] Ghosh, C. \& Madhav, M. R. (1994). Settlement Response of a Reinforced Shallow Earth Bed. Geotextiles and Geomembranes, 13: 643-656.

[6] Shukla, S. K. \& Chandra,S. (1994). A Generalized Mechanical Model for Geosynthetic-Reinforced Foundation Soil. Geotextiles and Geomembranes. 13: 813-825.

[7] Yin, J. H. (1997). A Nonlinear Model of Geosynthetic-Reinforced Granular Fill over Soft Soil. Geosynthetics International. 4 (5): 523-537.

[8] Maheshwari, P., Basudhar, P. K. \& Chandra, S. (2004). Analysis of Beams on Reinforced Granular Beds. Geosynthetics International. 11 (6): 470-480.

[9] Deb, K., Sivakugan, N., Chandra, S. \& Basudhar, P. K. (2007). Generalized Model for Geosynthetic-Reinforced Granular Fill-Soft Soil with Stone Columns. International Journal of Geomechanics, ASCE. 7 (4): 266-276.

[10] Deb, K., Chandra, S. \& Basudhar, P. K. (2010). Analysis of Extensible Geosynthetics and Stone Column-Reinforced Soil. Ground Improvement. 163 (4): 231 - 236.

[11] Maheshwari, P. \& Khatri, S. (2012). Generalized Model for Footings on Geosynthetic - Reinforced Granular Fill Stone Column Improved Soft Soil System. International Journal of Geotechnical Engineering. 6 (4): $403-414$.

[12] Zhou, W.-H., Zhao, L.-S. \& Li, X.-B. (2014). Analytical Study for Geosynthetic Reinforced Embankment on Elastic Foundation. Geotechnical Special Publication 238, Ground Improvement and Geosynthetics, ASCE, 444-451.

[13] Rajesh, S., Choudhary, K. \& Chandra, S. (2015). A Generalized Model for Geosynthetic Reinforced Railway Tracks Resting on soft Clays. International Journal of Numerical and Analytical Methods in Geomechanics. 39: $310-326$.

[14] Zhao, L.-S., Zhou, W.-H., Fatahi, B., Li,X.-B. \& Yuen, K.-V. (2016) A Dual Beam Model for GeosyntheticReinforced Granular Fill on an Elastic Foundation. Applied Mathematical Modelling. 40: 9254-9268.

[15] Som, N. N. \& Das, S. C. (2003). Theory and Practice of Foundation Design, Prentice - Hall of India Private Limited, New Delhi.

[16] Bowles, J. E. (1996). Foundation Analysis and Design. $5^{\text {th }}$ Edition, McGraw-Hill Book Co., Singapore.

[17] Das, B. M. (1999), Principles of Foundation Engineering. 4th Edition, PWS Publishing, USA.

[18] Desai, C. S. \& Abel, J. F. (1987). Introduction to the Finite Element Method: A Numerical Method for Engineering Analysis, CBS Publishers and Distributors, India. 